\title{
Frequency of Caesarean Section in Pregnancies with Borderline Amniotic Fluid Index at Term
}

\author{
Natasha Bushra, ${ }_{1}$ Khaula Zeeshan, ${ }^{2}$ Sara Ejaz, ${ }^{3}$ Javeria Mushtaq, ${ }^{4}$ Khadija Waheed, ${ }^{5}$ Amna Khanum ${ }^{6}$
}

\section{Abstract}

The increased risk of caesarean section after induced labour is well documented. Rate of induction of labour has doubled in the past decade from 10 to $20 \%$. Low Amniotic Fluid Index (AFI) as an isolated finding leads to increased obstetrical interventions but without any improvement in outcome.

Objectives: To determine the frequency of caesarean section due to failed induction in pregnancies at term with borderline AFI.

Patients and Methods: This cross-sectional study was conducted at Department of Obstetrics and Gynaecology, Unit-III, SIMS/Services Hospital, Lahore. The duration of study was one year from January,

\footnotetext{
${ }^{1}$ Senior Registrar, Dept of Obstetrics \& Gynaecology Services Hospital, Lahore

${ }^{2}$ Women Medical Officer, Dept of Obstetrics \& Gynaecology Lady Aitchison Hospital, Lahore

${ }^{6}$ Professor of Obstetrics \& Gynaecology

KEMU/ Lady Willingdon Hospital, Lahore.

${ }^{4}$ Assistant Professor of Obstetrics \& Gynaecology

FJMU/ Sir Ganga Ram Hospital, Lahore

${ }^{5}$ Assistant Professor of Obstetrics \& Gynaecology KEMU/Lady Aitchison Hospital, Lahore

${ }^{6}$ Assistant Professor of Obstetrics \& Gynaecology KEMU/Lady Aitchison Hospital, Lahore
}

Date of Submission: 24-10-2016

Date of $1^{\text {st }}$ Revision Received: 07-12-2016

Date of Acceptance for Publication: 15-04-2017

Conflict of Interest: None

Funding Source: None

\section{Contribution}

All Authors have contributed in Study Design, Data Collection, Data Analysis, Data Interpretation, Manuscript Writing and Approval.
2015 to December, 2015. A total of 150 patients were included in this study. AFI was measured by recent obstetric ultrasound. All patients with borderline AFI $(5-8 \mathrm{~cm})$ were included in the study. They were induced by glandin E2 gel. If induction of patients failed with two doses of glandin E2 gel, given vaginally 6 hours apart, patients were considered for cesarean section. The outcome measure was rate of caesarean section due to failed induction. All data were analyzed by SPSS version 20.

Results: Mean age of the patients was $30.34 \pm 6.68$ years. Mean gestational age was noted $38.34 \pm 1.05$ weeks. Out of 150 patients, $103(68.7 \%)$ were para $1-$ 3 and 47 patients $(31.3 \%)$ were para $4-6$. Caesarean section due to failed induction with borderline AFI was performed in 27 patients $(18.0 \%)$. Stratification with regard to age, gestational age and parity was carried out and was found significant only for gestational age being $>39$ weeks.

Conclusion: It is concluded that failed induction of labour at term in women with borderline AFI is not associated with increased risk of caesarean delivery. Keywords: Borderline; amniotic fluid index; Caesarean section; Failed induction.

\section{Introduction}

Amniotic fluid estimation is very important in pregnancy as increase or decrease in AFI is indicator of some complication in pregnancy. Oligohydramnios can complicate about $1-5 \%$ of pregnancies and most commonly it prompts labour induction. ${ }^{1}$ One of the most common ways to assess oligohydramnios is to check for Amniotic Fluid Index (AFI). AFI was first ever defined by Phelan in 1987 and it is now a validated tool for accurate estimation of amniotic fluid volume. $^{2,3}$ 
AFI is estimated by using ultrasound to measure the amount of amniotic fluid volume in 4 quadrants of the abdomens and all are summed up. AFI between 5 $8 \mathrm{~cm}$ is considered as borderline. ${ }^{4}$ Oligohydramnios and hence low or borderline AFI is considered associated with raised incidence of complications particularly in high risk pregnancies. These mainly include meconium aspiration after birth, reduced fetal heart rate, low Apgar score and increased incidence of cesarean section. ${ }^{4,5}$ AFI $\leq 5 \mathrm{~cm}$ is associated with all these complications during pregnancy; however, borderline AFI has shown different and variable results in many studies. Luo et al conducted a trial and compared the outcome between patients with borderline and normal AFI. They found no significant difference in fetal distress and neonatal mortality between two groups. However the incidence of cesarean rate was significantly higher in patients with borderline AFI. ${ }^{6}$

As there is no consensus in literature regarding the borderline AFI, we planned this study with the objecttive to determine the frequency of caesarean section due to failed induction in pregnancies at term with borderline AFI.

\section{Patients and Methods}

This cross-sectional study was conducted at Department of Obstetrics and Gynaecology, Unit-III, SIMS/ Services Hospital, Lahore. The total duration of study was one year spanning from January, 2015 to December, 2015. All female patients with singleton pregnancy presenting at term with Borderline AFI $(5-8$ $\mathrm{cm})$ were included in the study. Our exclusion criteria included: Previous perinatal loss; recurrent missed abortions; and intrauterine growth retardation. AFI was calculated on ultrasound by consultant sonologist and was labeled if it was $5-8 \mathrm{~cm}$. Sample size estimated was 150 using $95 \%$ confidence interval, $6 \%$ margin of error with an expected frequency of caesarean section due to failed induction in $15.8 \%$ cases with borderline AFI. ${ }^{10}$

All patients fulfilling inclusion and exclusion criteria were enrolled in the study. After informed consent, patient's bio-data including name, age, parity, duration of pregnancy were noted. All patients were induced by glandin E2 gel. If induction of patients failed with two doses of glandin E2 gel, given vaginally 6 hours apart, patients were considered for cesarean section. All data were analyzed using SPSS version 20.0. Quantitative variables like patient's age and gestational age were presented as mean \pm SD. Qualitative variables like caesarean section and parity were presented by calculating frequency and percentage. Also stratification of mode of delivery with respect to patient's age, gestational age and parity was done. Post-stratification Chi square test was applied. $\mathrm{P} \leq 0.05$ was taken as significant.

\section{Results}

A total of 150 patients were included in the study. Majority of the patients were between 20 - 30 years of age and mean age of the patients was $30.34 \pm 6.68$ years (Table 1). Mean gestational age was noted as $38.34 \pm 1.05$ weeks. Data regarding age, gestational age and parity is summarized in table 1. Caesarean section due to failed induction with borderline AFI was performed in 27 patients $(18.0 \%)$ while remaining 123 patients $(82 \%)$ delivered vaginally.

Table 1: Distribution of cases by age, gestational age and parity.

\begin{tabular}{|c|c|c|}
\hline & Number & Percentage \\
\hline Age (Year) & & \\
$18-30$ & 87 & 58 \\
$31-40$ & 45 & 30 \\
$41-45$ & 18 & 12 \\
\hline Gestational Age & & \\
$37-38$ & 93 & 62 \\
$39-40$ & 57 & 38 \\
\hline Parity & & \\
$1-3$ & 103 & 68.7 \\
$4-6$ & 47 & 31.3 \\
\hline
\end{tabular}

Stratification with regard to age, gestational age and parity was carried out and presented in table 2 .

\section{Discussion}

The objective of this study was to determine the frequency of cesarean section among patients presenting with borderline AFI due to failed induction. Phelan et al had introduced AFI between $5-8 \mathrm{~cm}$ as borderline; however two bulletins by American college of Obstetricians and Gynecologists have defined AFI greater than $5 \mathrm{~cm}$ as normal AFI. In this study, we 
had taken AFI of $5-8 \mathrm{~cm}$ being borderline and all these patients were included in the study.

Table 2: Stratification with respect to age, gestational age and Parity.

\begin{tabular}{|c|c|c|c|}
\hline \multirow[b]{2}{*}{ Variable } & \multicolumn{2}{|c|}{ Mode of delivery } & \multirow{2}{*}{$\begin{array}{l}\text { P- } \\
\text { value }\end{array}$} \\
\hline & $\begin{array}{c}\text { CS } \\
\mathbf{N}(\%)\end{array}$ & $\begin{array}{c}\text { NVD } \\
\mathbf{N}(\%)\end{array}$ & \\
\hline Age (years) & & & \\
\hline $18-30$ & 14 & 73 & 0 758 \\
\hline $31-40$ & 09 & 36 & 0.158 \\
\hline $41-45$ & 04 & 14 & \\
\hline Gestational age (weeks) & & & \\
\hline $37-38$ & 12 & 81 & 0.037 \\
\hline $39-40$ & 15 & 42 & \\
\hline Parity & & & \\
\hline $1-3$ & 18 & 85 & 0.804 \\
\hline $4-6$ & 09 & 38 & \\
\hline
\end{tabular}

The amount of amniotic fluid varies with gestational age and it plateaus at $22-39$ weeks of gestation with the amount being $700-800 \mathrm{ml}$ and it corresponds to AFI of $14-15 \mathrm{~cm}$. The low AFI or decrease in amniotic fluid volume has many complications and one of these is the increase incidence of cesarean section. In this study we found that the incidence of cesarean in patients with borderline AFI was $18 \%$. Choi et al conducted a trial to compare outcomes between patients with borderline and normal AFI, and they found that cesarean rate in patients with borderline AFI was $12.4 \%$, however the difference in two groups was not significant. ${ }^{7}$ Petrozella $\mathrm{LN}$ et al reported the frequency of cesarean section as $9 \%$ in patients with borderline AFI. ${ }^{8}$ Also in this study we stratified our outcome with relation to gestational age, age of mother and parity, but all results were found not significant except the gestational age being > 39 weeks. Kreiser et al reported that there was no significant difference in cesarean rate between patients with normal and borderline AFI. ${ }^{9}$ However Alchalabi et al reported in their trial that the incidence of cesarean was significantly higher in patients with $\mathrm{AFI}<5$ than those having AFI $>5 .{ }^{10}$ Chate et al found in their trial that the incidence of cesarean in patients with Oligohydramnios was $64 \%$ and it was significantly higher than those not having oligohydramnios. ${ }^{11}$
There were few limitations in our study. We have not compared the patients with borderline AFI with those having normal AFI. Also in this study we have not considered the neonatal complications which may be associated with the borderline or low AFI.

On the basis of this study, we conclude that the frequency of cesarean section in patients with borderline AFI in our setup is almost comparable to those from developed countries. However, we recommend more multicenter randomized trials on the topic in our country.

\section{References}

1. Akhter N, Taing S, Mir IN, Ahmad N, Sheikh TA, Ahmad MM. Antepartum transabdominal amnioinfusion in oligohydramnios-a comparative study. International Journal of Reproduction, Contraception, Obstetrics and Gynecology. 2015;4:1181-4.

2. Phelan JP, Smith CV, Broussard P, Small M. Amniotic fluid volume assessment with the four-quadrant technique at 36-42 weeks' gestation. J. Reprod. Med. 1987; 32:540-2.

3. Kehl S, Schelkle A, Thomas A, Puhl A, Meqdad K, Tuschy B, et al. Single deepest vertical pocket or amniotic fluid index as evaluation test for predicting adverse pregnancy outcome (SAFE trial): a multicenter, openlabel, randomized controlled trial. Ultrasound Obstet. Gynecol. 2016;47:674-9.

4. Asgharnia M, Faraji R, Salamat F, Ashrafkhani B, Dalil Heirati SF, Naimian S. Perinatal outcomes of pregnancies with borderline versus normal amniotic fluid index. Iran J Reprod Med. 2013;11:705-10.

5. Agrawal S, Agrawal V, Yadav S. Comparative study of amniotic fluid index in normal \& high risk pregnancy complicated by PIH. Ind J Obst Gynaecol Res. 2015;2: 242-5.

6. Luo X, Huang Y, Liang R. [Analysis of 196 cases of trial of labor with borderline oligohydramnios assessed by ultrasound]. Zhonghua fu chan ke za zhi. 1998;33: 585-7.

7. Choi SR. Borderline amniotic fluid index and perinatal outcomes in the uncomplicated term pregnancy. J. Matern. Fetal Neonatal Med. 2016;29:457-60.

8. Petrozella LN, Dashe JS, McIntire DD, Leveno KJ. Clinical significance of borderline amniotic fluid index and oligohydramnios in preterm pregnancy. Obstet. Gynecol. 2011;117:338-42.

9. Kreiser D, el-Sayed YY, Sorem KA, Chitkara U, Holbrook Jr R, Druzin ML. Decreased amniotic fluid index in low-risk pregnancy. J. Reprod. Med. 2001;46:743-6. 
10. Alchalabi HA, Obeidat BR, Jallad MF, Khader YS. Induction of Labor and Perinatal Outcome: The Impact of The Amniotic Fluid Index. Eur. J. Obstet. Gynecol. Reprod. Biol. 2006;129:124-7.
11. Chate P, Khatri M, Hariharan C. Pregnancy outcome after diagnosis of oligohydramnios at term. Int J Reprod Contracept Obstet Gynecol. 2013;2:23-6. 